\title{
The cognitive biases of human mind in accepting and transmitting religious and theological beliefs: An analysis based on the cognitive science of religion
}

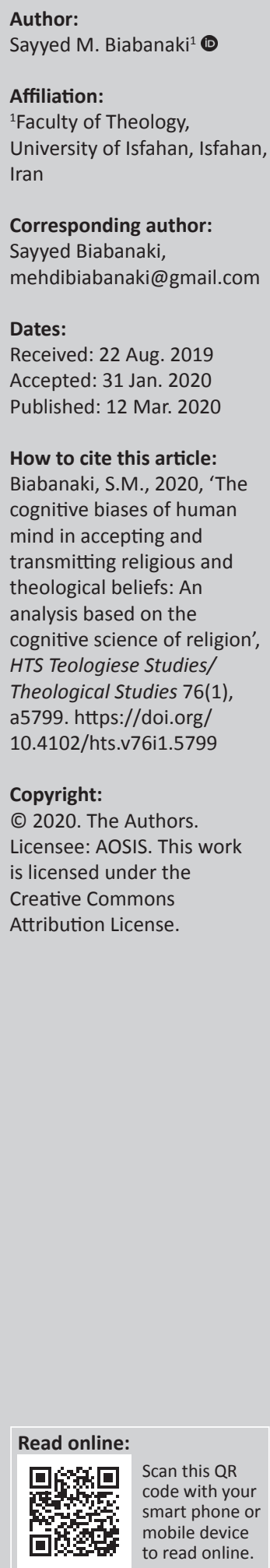

The cognitive science of religion (CSR) is an emerging field of cognitive science that gathers insights from different disciplines to explain how humans acquire and transmit religious beliefs. For the CSR scholars, the human mental tools have specific biases that make them susceptible to acceptance and transmission of religious beliefs. This article examines the characteristics of these biases and how they work, and shows that although our innate cognitive tendencies make our minds generally receptive to religion, they do not explain the emergence and endurance of specific religious beliefs in a particular culture. We will also show that although advocates of CSR study religion as a 'natural' phenomenon, and seek to discover the natural causes of the formation, acceptance, transmission and prevalence of religious beliefs, their efforts do not lead to decrease the validity of religious beliefs and rejection of 'non-natural' explanations of religious beliefs.

Keywords: cognitive science of religion; cognitive bias; intuitive religious beliefs; reflective religious beliefs.

\section{Introduction}

Cognitive science is an interdisciplinary study that attempts to scientifically study what is the mind and how it functions. Its origins date back to the mid-1950s when researchers in various fields began developing theories of mind based on complex representations and computational methods (Thagard 2018:1). Various disciplines such as philosophy, psychology, artificial intelligence, neuroscience, linguistics, anthropology and archaeology are used in cognitive science studies. There are a variety of issues, such as perception, memory, conceptualisation, learning, reasoning, decision-making and imagination, that cognitive scientists examine to find the mental mechanisms.

The cognitive science of religion (CSR) is an emerging branch of the field that seeks to explain the formation, acceptance, transmission and prevalence of religious beliefs based on the function of the mind and its cognitive mechanisms. This approach has led to the development of a thriving research programme on the 'natural' origins of religion. Cognitive science of religion researchers examine how the structure of our minds influences the continued emergence and cultural success of religious beliefs, such as beliefs in supernatural beings, beliefs in spirits and beliefs in the afterlife that exist across cultures. According to CSR researchers, the human mind at birth is not neutral with respect to religious beliefs. In other words, human's mental mechanisms have specific biases that make them prone to accepting religious beliefs. There are a few basic questions about this hypothesis:

1. Where did these biases come from?

2. What are these biases and what are their characteristics?

3. How do these biases work?

These are the questions that this article will address. Accordingly, the following steps are necessary:

1. Firstly, consider the distinction that cognitive science researchers make between intuitive and reflective beliefs, and the distinction CSR researchers make between religious and theological beliefs (this is dealt with in the section 'Religious beliefs and theological beliefs').

2. Then introduce the content and context biases as well as how they operate in the acceptance and transmission of religious beliefs (these are topics of the sections 'Content and context biases' and 'Applying content bias in the acceptance and transmission of religious belief'). 
3. Next, examine the application of context biases in the reception and transmission of theological beliefs (this is discussed in the section 'Applying context biases to the acceptance and transmission of theological beliefs').

4. Finally, analyse two basic questions about the above cognitive biases and how they function: (1) do the attempt by CSR researchers to find natural mechanisms involved in the acceptance and transmission of religious beliefs lead to discredit such beliefs? and (2) do the natural explanations of CSR provide sufficient explanations in this regard and explain exclusively the acceptance and transmission of such beliefs? (this is analysed in the section 'The natural and unnatural foundations of religious beliefs')

The purpose of this article is to examine the characteristics of the cognitive biases involved in the reception and transmission of religious beliefs and to analyse how they function, and to show that although our innate cognitive tendencies make our minds generally receptive to religion, they do not explain the emergence and endurance of specific religious beliefs in a particular culture. It will also show that although advocates of CSR study religion as a 'natural' phenomenon, and seek to discover the natural causes of the formation, acceptance, transmission and prevalence of religious beliefs, their efforts do not lead to decrease the validity of religious beliefs and rejection of 'non-natural' explanations of them.

\section{Religious beliefs and theological beliefs}

One of the basic concepts often used by cognitive science researchers is the distinction between 'intuitive beliefs' and 'reflective beliefs'. Sperber's (1997) well-known essay, 'Intuitive and reflective beliefs', explains the distinction that is often cited by cognitive science researchers. Intuitive beliefs are those beliefs that are not consciously acquired through thought and reflection, but are automatically produced by our minds. These beliefs are not consciously evaluated or verified; they just seem 'intuitive' (Barrett 2011:48).

According to cognitive science researchers, these intuitive beliefs are not taught to children through explicit verbal instruction. Rather, all children in all times and all cultures, rapidly and uniformly, acquire these beliefs and do not need any special environment or training or guidance to acquire them. Therefore, because intuitive beliefs are predominantly gauged in non-verbal terms, we have a considerable amount of information on children's intuitive beliefs. For example, by examining children's perspectives, we know that children intuitively believe that solid objects cannot pass directly through other solid objects. They also believe that unsupported objects fall. In addition, they believe that one inanimate object must be moved by another and cannot move at its own will (Barrett 2009:78-79).

On the contrary, reflective beliefs are beliefs that are acquired through conscious reflection and thought. When we are asked whether we believe in such a thing or not, the answer we give is what is called 'reflective belief'.

For example, when people say that they believe that the Earth orbits the sun, or that things fall because of the Earth's gravity, they actually express reflective beliefs.

Along with the above distinction, CSR scholars also distinguish between 'general religious beliefs' and 'theological beliefs'. The 'general religious beliefs', also called 'folk religious beliefs' and 'ordinary religious beliefs', refer to those religious beliefs that ordinary people in different cultures believe in. These beliefs include belief in supernatural agents (such as God), belief in afterlife, belief in spirits, belief in miraculous events and so on. The notable feature of such beliefs is their widespread presence throughout many cultures and most periods of human life. Many empirical studies have been carried out to confirm this feature (Powell \& Clarke 2012:458). For example, anthropologists propose that religions that share supernatural characteristics (such as belief in God, afterlife, the effect of prayer on the natural course of events, religious practices, etc.) are found in many cultures on the earth (Henig 2007:1). In addition, crosscultural studies of religion show that there are significant parallels between different cultures in both religious beliefs (such as belief in supernatural agents) and religious practices (such as religious rituals).

For CSR scholars, these widespread cultural similarities of general religious beliefs are not because of random processes; rather, general religious beliefs are rooted in the underlying structures of our minds and all humans are carriers of such beliefs (henceforth, I call 'general religious beliefs' briefly 'religious beliefs').

In contrast, 'theological beliefs' are institutionalised systematic reflections on religious beliefs and their relationship with other beliefs (De Cruz 2014:490). The Trinity in Christianity and Brahman in Hinduism are examples of theological beliefs. These beliefs are the product of deliberate reflection, emerging in a particular culture and lacking the prevalence of religious beliefs.

It is clear from what has been said that, in fact, theological beliefs are reflective beliefs, and religious beliefs are intuitive beliefs. Therefore, we can distinguish between theological beliefs and religious beliefs as defined by CSR scholars (Barrett 2009:77-79, 2007:770; Boyer 2002:283; De Cruz 2014:488; Lim 2016:955-957):

1. Religious beliefs emerge relatively easily without formal education (or with little or no elementary education) and are stabilised in childhood. While the acquisition of theological beliefs requires years of study and deliberation, they are often contemplated by experts and scholars.

2. Religious beliefs are widespread across many cultures (past and present), while theological beliefs are less culturally pervasive and confined mainly to large 
societies. In other words, a theological belief largely belongs to a particular culture and does not have the generality of religious beliefs.

3. Religious beliefs do not require widespread cultural support, such as written texts, and so on, for its transmission and include a rich array of practices, rituals, exclusive clothing and food prohibitions. Theological beliefs, however, are often learnt in linguistic formats and stored in the mind. In other words, theology primarily consists of reading, writing and reflection, and is mainly carried out by experts and scholars.

4. Religious beliefs are present in many cultures in a relatively stable and successful way and are passed on from generation to generation. On the contrary, theological concerns and solutions are subject to change over time and show considerable variation amongst sects and religions.

The ubiquitous presence of religious beliefs and their widespread and sustained transmission across cultures has prompted CSR scholars to organise a comprehensive effort to understand and explain why this phenomenon occurs. Over the past two decades, CSR has made remarkable progress in understanding the cognitive foundations of religious beliefs and practices. These advances have been both theoretical and providing experimental and laboratory evidence in this regard. Much of this effort has focused on the biases of the human mind in accepting religious beliefs. Experimental and laboratory efforts have been made primarily to discover and quantify these biases and understand how they work, and theoretical efforts have been focused on modelling and integrating this evidence. Of course, as CSR scholars assert that the acquisition of religious beliefs does not require linguistic and verbal formats (such as teaching, reading and writing, etc.), so much of the experimental work is performed with children. In addition, children's cognitive mechanisms is not yet intertwined with formal and theological doctrines in the culture in which they are born, and so it will be more accurate to discover the cognitive biases and mechanisms involved in their acceptance of religious beliefs. The main lines of these efforts are discussed next.

\section{Content and context biases}

It was mentioned in the previous section that CSR scholars focus on the religious beliefs that are relatively stable and enduring across cultures and are passed down from generation to generation. For CSR scholars, this astonishing and sustained transmission of religious beliefs is rooted in the representation of those beliefs within the human mind. In other words, the structures and particular orientations of the human mind have provided the basis for the successful and sustained transmission of religious beliefs. These particular mental orientations or tendencies in the processing and evaluation of input information to the mind are called 'cognitive biases'. The question now is a follows: what are these cognitive biases about religious beliefs and how do they work?
Cognitive science of religion researchers divide cognitive biases into two types: content biases and context biases (Gervais et al. 2011:391). Content biases are biases that direct our attention to the content of representations and input information to the mind. These biases evaluate and process beliefs with criteria such as its consistency with our earlier beliefs, its ease of understanding or processing for the mind and whether it is surprising or interesting for the mind.

In contrast, context biases are not concerned with the content of beliefs and input information, but rather with the context in which those beliefs are transmitted, such as the reliability or validity of the source of belief production (De Cruz 2014:489). In the following, the application of each of these two types of bias to the acceptance and transmission of religious and theological beliefs is examined.

\section{Applying content bias in the acceptance and transmission of religious beliefs}

Much research has been performed in CSR on content bias as a way to understand religious beliefs. Boyer (2002), Claidiere and Sperber (2007) and some other cognitive anthropologists have studied the role of content biases in cultural transmission. Gervais et al. (2011) have studied the role of content biases in reflective religious beliefs. Bloom (2004) and Bering, McLeod and Shackelford (2005) have focussed on intuitive ontologies as an important type of content bias. The question now is, 'what kind of content bias is involved in the acceptance and transmission of religious beliefs?' In the following, we will analyse three of the most important of these biases. However, because of the empirical nature of CSR, the number and cases of these biases may change with more research. So, we first introduce the four basic criteria that most CSR researchers seem to employ to identify content biases based on these criteria. In fact, in their view (Barrett 2007; Boyer 2003), these criteria are the principles governing the processes and evaluations of the human mind regarding religious beliefs. These criteria are following:

1. Religious beliefs that are easily remembered are better candidates for successful acceptance and transmission than those that are hardly remembered (if all other conditions are equal).

2. Religious beliefs that fulfil human mind's intuitive expectations are more likely to be accepted and expanded because they are easier to understand and process. In contrast, a religious belief that often violates the intuitive expectations of human minds is likely to be destroyed because it imposes a heavy burden on the mind for processing.

3. The more surprising and interesting a religious belief is for the human mind, the more inclined the mind is to accept and transmit it. Accordingly, human minds find some religious beliefs more attractive and easier to accept and transmit than other beliefs. 
4. Religious beliefs that do not conform to our background beliefs are less likely to be accepted and developed.

Based on the criteria outlined above, CSR researchers try to discover cognitive biases that are consistent with the above criteria to explain the widespread acceptance of religious beliefs across cultures and their sustained and successful transmission. In the following, three of the most important biases in this regard are analysed.

\section{Intuitive dualism}

One of the most important content biases that CSR scholars cite is 'intuitive dualism', first described by Paul Bloom, one of the leading CSR scholars, in the book Descartes' Baby (Bloom 2004:177). Bloom argues that humans are 'intuitive dualists', in the sense that they naturally believe that part of a person is immaterial (the soul) and can survive after the physical death. For Bloom, this intuitive dualism is the result of our intuitive ontological distinction between minds and physical bodies. Because CSR scholars believe that 'intuitive ontology' underlies most of our content biases, it needs to be discussed a little.

'Intuitive ontology' is a limited set of our evolved expectations that emerged in early childhood, guiding our reasoning about physical, psychological and biological phenomena (De Cruz 2014:489). It is 'intuitive' in the sense that it is not the product of deliberate reflection or scientific or philosophical research. In other words, these intuitive expectations are inherent in our minds, activated in us from an early age and always accompany our other beliefs and reasons. For example, suppose someone is trapped in a room with metal walls. If he or she argues that he or she cannot escape the room, all humans will find this reason compelling because they know by their 'intuitive physics' that it is not possible for a solid object to pass through another solid object. Table 1 presents some examples of intuitive ontologies.

Bloom (2004) believes that as we have different evolved inference systems for psychology and physics, we intuitively distinguish between minds and physical bodies.

After Bloom's (2004) theory was suggested, experimental studies were conducted to evaluate his theory, most of which supported Bloom's theory. For example, Barrett et al. (2013)

\begin{tabular}{|c|c|c|}
\hline $\begin{array}{l}\text { Intuitive } \\
\text { ontologies }\end{array}$ & The basic question & Example \\
\hline Intuitive physics & $\begin{array}{l}\text { How do inanimate } \\
\text { objects move? }\end{array}$ & $\begin{array}{l}\text { - Solid objects cannot pass through } \\
\text { other solid objects. } \\
\text { - An object that has no support } \\
\text { falls down. }\end{array}$ \\
\hline Intuitive biology & $\begin{array}{l}\text { How do living things } \\
\text { develop and behave? }\end{array}$ & $\begin{array}{l}\text { - Animals give birth to babies similar } \\
\text { to themselves. } \\
\text { - Living things act to obtain feeding. }\end{array}$ \\
\hline $\begin{array}{l}\text { Intuitive } \\
\text { psychology }\end{array}$ & $\begin{array}{l}\text { How do the intentional } \\
\text { agents behave? }\end{array}$ & $\begin{array}{l}\text { - Agents are working to achieve their } \\
\text { desires. } \\
\text { - Actions are guided by beliefs. } \\
\text { - Satisfied desires generate positive } \\
\text { emotions. }\end{array}$ \\
\hline
\end{tabular}

showed that 4-year-old children understand that mental states can be distinct from the physical world. Children understand that intentional agents can hold false beliefs that are different from things in the world (Barrett et al. 2013:1471-2954). In addition, many studies of human beliefs in afterlife have shown that people in different cultures continue to attribute mental states to a person even after his or her physical death. In one of the most famous of these studies, Bering et al. (2005) showed that 5-year-olds, even those who grew up in secular families, have a strong tendency to believe that a dead mouse baby (eaten by a crocodile) can continue to feel the nostalgia and the loss of her mother. Cognitive science of religion researchers conclude from the evidence that the belief that 'mental states are distinct from the physical body and can survive after the physical death' has become a 'natural' and 'cognitive bias' for the human mind. This bias plays an important role in the widespread acceptance of the belief in spirits and the afterlife, and is the natural cause of the widespread transmission of these beliefs in many human cultures.

However, research in this area does not end there. Recent research has shown that imagining a dead person who is completely without body is very difficult for the human mind and cognitive mechanism (does not satisfy criterion 2). In other words, a 'strong dualism' in the Cartesian sense that completely distinguishes mental states from the physical body and ultimately leads to the survival of the soul alone is very difficult to process for the human mind. Cognitive science of religion scholars therefore regard humans as 'weak intuitive dualists', that is, humans perceive people as a composite entity of mind and body that although both are ontologically distinct, they are both present in our conception of the personality of a person in the afterlife (Hodge 2011:367-389). As a result, humans' belief in the afterlife that emphasises the continuity of the soul also includes some physical elements, such as the body. Some CSR scholars use this bias of the human mind to explain why in most religions, paradise has physical and material elements such as water gardens and trees intertwined (De Cruz 2014:490). Accordingly, such religious concepts are easily accepted and transmitted because they are consistent with the intuitive expectations of our cognitive mechanisms.

\section{Design and purpose in the natural world}

Empirical evidence and research in the field of CSR show that the human mind has a particular tendency to purposefully view the natural world and provide teleological reasons for it. For example, Kelemen's $(2003,2004)$ research on American and British children has shown that children have a strong bias towards purposeful viewing of the natural world, even having never been taught by parents and teachers. Children tend to say that the rocks are sharp not because of some physical processes, but because being sharp prevents animals from sitting on the rocks. Kelemen (2003:201) asserts that children extend this free teleology to living and non-living natural things. Recent research has shown that even 12-month-olds understand that only intentional agents can create order from disorder (Barrett 2007:774). 
Also, Evans (2000:221-254) in a study of 5-12-year-old children has shown that children prefer creationist approaches to evolutionary ones regardless of their parents' beliefs about the origins of animals and humans. These empirical evidence shows that children are born with a strong bias to see the world as purposefully designed. But designed by who?

Barrett's (2007:774) research has shown that preschoolers see god as the origin of design in nature.

Barrett (2007) concludes from the empirical evidence that these findings suggest that children are equipped with the concept of a creator god. Kelemen (2004:295) also concludes from his empirical research that children have a special acceptance of a creator god because of this 'theological bias'. He calls children 'intuitive theists'. Therefore, there is the cognitive bias in humans to view the natural world as designed and purposeful. This cognitive bias enables humans to accept and transmit the concept of creator god.

\section{Religious concepts as minimally counter-intuitive concepts}

Pascal Boyer, another prominent researcher in the field of CSR, presented research based on intuitive ontology that has been accepted by many researchers in the field. In his view, religious concepts owe their cultural endurance to their 'minimal counter-intuitivity' (Boyer 2000:107). In the previous section, we discussed that for CSR researchers an important criterion for easy acceptance and rapid transfer of an idea or concept is the complexity of the concept or idea. Concepts that satisfy our cognitive mechanism's intuitive expectations are more easily remembered and transmitted (Boyer 2000:101-105). In other words, concepts that are completely intuitive are well spread. On the contrary, concepts that override the intuitive expectations of our cognitive mechanism will be extremely difficult to understand, remember and transmit to others. Accordingly, CSR researchers divide the counter-intuitive concepts into two categories: 'minimally counter-intuitive' (MCI) and 'maximally counter-intuitive'. To clarify this classification, consider the following three ideas:

1. a carpet that is spread in the palace and people walk on it

2. a carpet that is spread in the palace and people walk on it, but sometimes fly

3. a carpet that is spread in the palace and people walk on it, but sometimes fly and do things, can experience the past, can read the minds of others and can disappear.

Carpet (1) is completely intuitive, while carpet (3) is maximally counter-intuitive because it has four properties that violate the intuitive expectations of our cognitive mechanism (our intuitive ontology): an object without support that does not fall, experience the past, mind reading and disappearing. Hence, it is called 'maximally counterintuitive'. But carpet (2) is MCI, for it only violates one of our cognitive mechanism's intuitive expectations: an object without support that does not fall. Concepts that often satisfy our intuitive expectations and violate only a limited number of them are called MCI.

Boyer's research (2000) has shown that the MCI concepts are better remembered than either the completely intuitive concepts or the maximally counter-intuitive ones and are more easily transferred from one person to another (Boyer \& Ramble 2001:535). Completely intuitive concepts attract little attention. Maximally counter-intuitive concepts place a heavy burden on our conceptual and cognitive systems, so we are reluctant to remember and transmit them. In contrast, MCI concepts do not impose a heavy burden on our conceptual and cognitive systems, and at the same time attract more attention. In other words, a few counter-intuitive features make our cognitive system more sensitive to it and more inclined to think about it and to remember it than intuitive concepts. On the other hand, because it does not impose a heavy burden on our cognitive system, we tend not to dismiss or forget it, but rather to pass it onto others. Thus, according to MCI theory, we naturally have this cognitive bias: we tend to memorise MCI concepts, remember them better and pass them onto others. This cognitive bias is because of two memory advantages that have MCI concepts:

1. They are very interesting with the violation of our intuitive ontology (criterion 3).

2. They do not put too much pressure on our cognitive system, with only a few limited violations of our intuitive expectations and the maintenance of our other intuitive cognitions (criterion 2).

There has been major empirical research that supports Boyer's idea (Barrett 2007; Barrett \& Nyhof 2001; Boyer \& Ramble 2001; Lisdorf 2001). For example, Barrett and his colleagues in an empirical study have shown that MCI concepts (such as speaking chairs) are more commonly remembered by humans. In contrast, concepts that are fully in line with our intuitive expectations (such as wooden chairs) or concepts that are completely counter-intuitive (such as speaking chairs that speak multiple languages) do not have this property (Barrett \& Nyhof 2001:69-100).

What is the relationship between MCI and religious beliefs? For CSR researchers, those religious beliefs that are widespread across all human cultures have MCI character. For example, Boyer argues that ordinary people around the world have the cognitive tendency to regard the concept of 'god' as an MCI concept, that is to say, 'an agent that is minimally counter-intuitive' (Boyer 2003:124). In addition, he argues that part of the reason that such a concept is successful, that it is better remembered and transmitted so quickly, is that it does not impose a heavy burden on our cognitive system.

Another example is the concept of 'soul'. This concept violates our intuitive physical expectations because, from the human perspective, the soul can pass through walls or disappear at will, but it is also compatible with our intuitive psychology because like other intentional agents, it has 
beliefs, desires and emotions. The violation of intuitive physics makes it noticeable, and its compatibility with intuitive psychology makes it easy to process for our cognitive system. These two characteristics can explain the cultural success of the concept of 'soul' throughout human cultures (De Cruz 2014:490). Therefore, the counter-intuitiveness of religious concepts and beliefs is not only an obstacle to their widespread acceptance, but also is itself a cognitive advantage to such concepts. Accordingly, religious concepts violate only some of our intuitive ontology (not all of them), but it makes these concepts more relevant to our cognitive mechanism and makes it easier to accept and transmit. Therefore, religious concepts and beliefs are not a separate piece for us to impose on our cognitive mechanism, but our cognitive system has a particular acceptance of such concepts and beliefs.

So far, three content biases that play an important role in the acceptance and transmission of religious beliefs have been examined. All the three were related to our intuitive ontology. This suggests that intuitive ontology plays a central role in explaining the acceptance and transmission of religious beliefs in the CSR domain. The question now is, 'do theological beliefs also have such biases in our cognitive system?' In the next section, this question is considered.

\section{Applying context biases to the acceptance and transmission of theological beliefs}

In the previous section, it is stated that content biases are concerned with the content of the belief, while context biases relate to the context in which the belief is transmitted. Also, in the previous section, it was concluded that content biases play an important role in the acceptance and transmission of religious beliefs. Three questions now arise:

1. Are content biases also involved in the reception and transmission of theological beliefs?

2. Are context biases involved in the reception and transmission of religious beliefs?

3. Are context biases involved in the reception and transmission of theological beliefs?

To answer these questions, we need to consider context bias and its application in the CSR field. Some of the most important context biases that CSR researchers cite are (De Cruz 2014; Edwards 2009; Mercier \& Sperber 2011):

1. The presence of other believers: The presence of other people who believe in what I believe makes me more inclined to accept and transmit that belief. In other words, we have the bias that our confidence in and acceptance of a religious belief will increase with the presence of other believers.

2. The presence of rituals: Research has shown that religious beliefs associated with private rituals have higher acceptance and transmission.

3. Trust in the missionary of a belief (people in authority such as bishops and priests): The greater our confidence in the missionary of a religious belief, the greater our tendency to accept that belief - even if we do not know it accurately.

It is well known that none of these biases relate to the content of the religious belief, but rather to the context in which that belief is transmitted. Hence, they are called 'context biases'. To illustrate, let us look at an example of the use of context biases in explaining the acceptance and transmission of religious or theological beliefs.

Consider the belief in the 'Trinity' in Christianity. This belief promotes a completely counter-intuitive notion of 'God': God is three consubstantial persons or hypostases, is eternal, yet born of a mortal virgin. Such complexity goes far beyond the MCI concepts that ordinary religious beliefs possess. So, why does such a belief persist amongst Christians and is passed down from generation to generation? This question can be answered with the help of context biases. Accordingly, the belief in the Trinity remains a theological doctrine in Christianity because the following context biases support this belief:

1. The presence of other Christians leads a Christian to accept the Trinity, even if he or she has no intuitive understanding of this doctrine.

2. The existence of Trinity-related rituals has increased the acceptance of such beliefs amongst Christians.

3. The public's confidence in the authority of the priests and bishops, who propagate such a doctrine, has reinforced the belief in it.

These context biases explain why Christian believers continue to accept and transmit the belief in the Trinity, although they do not have an intuitive understanding of it. By examining this and other examples provided by CSR researchers, a few basic points can be reached to answer the questions of this section:

1. Context biases are mainly used to explain theological beliefs, not religious beliefs. The Trinity is an example of these theological beliefs. A theological belief, as we explained at the beginning of this article, belongs to a particular culture and does not have the generality and pervasiveness of a religious belief. It seems that the connection between the context biases and theological beliefs is that a theological belief belongs to a particular culture and is therefore accepted and transmitted in the context of that culture. Thus, the answer to the second and third questions at the beginning of this section is that although the context biases do not play a significant role in the acceptance and transmission of religious beliefs, they play a central role in the acceptance and transmission of theological beliefs.

2. Content biases are mainly used to explain religious beliefs, not theological beliefs. This also seems to be because theological beliefs are formed in the context of a particular culture, and therefore require contexts and elements of the same culture to transmit, while content bias has nothing to do with the context of a belief, and it 


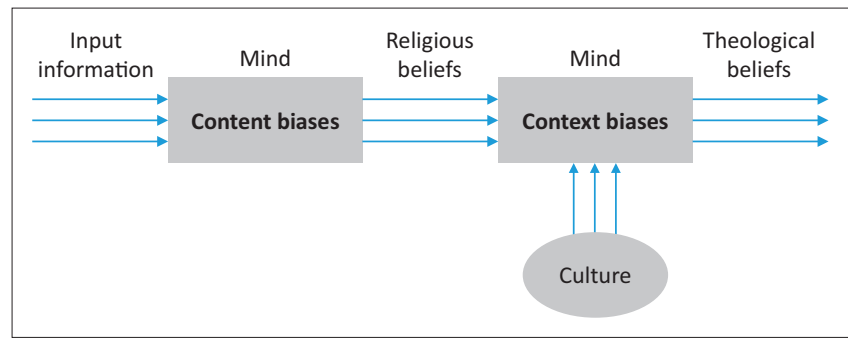

FIGURE 1: Relationship between religious or theological beliefs and content or context cognitive biases.

only deals with the content of that belief (answering the first question).

3. The conclusion of the above two points is that there is a relationship between religious or theological beliefs and content or context biases shown in Figure 1. Accordingly, content biases operate on religious beliefs and facilitate their acceptance and transmission. As these biases are related to the structure of the mind and its inherent function and humans are born with such biases, such beliefs are widely accepted by humans across cultures. However, while content biases can explain why some religious beliefs are memorable and widespread, they cannot explain why people are committed to and believe in the reflective religious beliefs (theological beliefs) in a particular culture. In contrast, context biases play a central role in the prevalence of theological beliefs. The context biases are shaped by human cultural interactions and act on theological beliefs within a particular culture.

This process actually provides a natural explanation of the widespread prevalence of religious beliefs across cultures and of theological beliefs being confined to a particular culture. Accordingly, humans in all cultures have a special tendency for accepting religious beliefs (such as belief in god and afterlife), which are rooted in our intuitive ontologies. In fact, humans are equipped with tools (content biases) that make them prone to accept religious beliefs. In contrast, context biases are not shaped by our intuitive ontology and depend on the context in which a belief is transmitted. In the context of Christian theology, beliefs such as the Trinity are widespread, and in the context of Islamic theology, beliefs such as monotheism are widespread. In other words, all children are born with beliefs such as belief in god and afterlife that form their general religious beliefs.

Then, by growing up within a particular culture, their general religious beliefs become theological beliefs. The theological beliefs of a person can be influenced by social and cultural factors, but religious beliefs, which are rooted in the intrinsic structures of the human mind, cannot be changed and always accompany the person.

\section{The natural and unnatural foundations of religious beliefs}

In the final section of the article, we need to answer two questions:
1. Does the attempt by CSR researchers to find natural mechanisms involved in the acceptance and transmission of religious beliefs mean to discredit such beliefs?

2. Do natural CSR explanations of religious beliefs provide sufficient explanations in this regard and explain exclusively the acceptance and transmission of such beliefs?

Regarding the first question, we have to note that one of the common mistakes in some scientific and philosophical texts is the confusion between the natural and rational foundations of religious beliefs. Hume (1956:21) makes this distinction in his book The Natural History of Religion. He distinguishes between two questions about religion: (1) questions about the rational foundations of religious belief and (2) questions about the natural foundations of religious beliefs (Hume 1956:21). The first question is an epistemological question that examines whether or not religious beliefs are justified: to what extent is 'belief in the existence of God' justified? Or what are the rational arguments for this belief? The second question, however, seeks to investigate the origin of such beliefs in human nature: what natural causes led humans to believe in God? Indeed, the second question seeks to provide causal explanations of the origin of religious beliefs.

Some philosophers try to regard cognitive explanations of religious beliefs as arguments that reject or discredit religion. But from the research produced in the field of CSR, it is clear that finding a natural source for religious belief or describing the cognitive mechanisms associated with it does not in any way mean rejecting or discrediting religion. This is performed for many of our perceptions and cognitions, that is, trying to introduce a natural source for our cognitions or describing the mechanisms involved in perception. But no one imagines that such an effort would discredit our beliefs. Suppose, for example, that the cognitive mechanisms in our brain that cause us to perceive a flower or find the sum of ' $2+3$ ' are discovered. Does this mean that the flower we are seeing does not exist or is our perception of it invalid or the result obtained ('5') is invalid?

Thus, cognitive explanations for the acceptance and transmission of religious beliefs are an attempt at the second question, which is by no means the answer to the first question. Defenders of cognitive explanations study religion as a natural phenomenon and seek to discover the natural causes of the formation, acceptance, reinforcement and prevalence of religious beliefs. So, they need to distinguish between reasons for believing in religious beliefs and an explanatory view of why people believe in such beliefs, and, of course, focusing on the latter without using it to answer the first.

Concerning the second question, some CSR scholars emphasise that their attempt to find the natural causes of religious beliefs is not an 'exclusive' position on the origin of such beliefs. In other words, it is not that religious beliefs were formed solely on the basis of natural causes and no 
other causes were involved in their formation. For example, Barrett (2007) asserts that:

... [CSR is a] complementary to the activities of other religion scholars from many disciplinary perspectives, a stance of explanatory non-exclusivity. CSR does not pretend to exhaustively explain everything that might be called 'religion' (provocative book titles aside). Rather, it seeks to detail the basic cognitive structure of thought and action that might be deemed religious and invites historians, anthropologists, sociologists, psychologists and other religion scholars to fill in the hows and whys of particular religious phenomena. (p. 769)

This strategy allows CSR not to conflict with an approach that seeks supernatural causes for religious beliefs, but as a complement to it. In other words, one can use both natural explanations of the origin of religious beliefs (as CSR provides) and supernatural explanations at another level. These are two levels of explanation that are intertwined and we need both to provide a complete description. In our view, there are two supernatural areas of explanation regarding the mechanism of acceptance and transmission of religious beliefs that need to be added to natural explanations in this regard in order to obtain a relatively complete picture of this phenomenon:

1. paying attention to the role of the prophets, the clergy and their teachings in the acceptance and transmission of religious beliefs in human societies

2. considering the ontological role of God and other supernatural agents in the acceptance and transmission of religious beliefs in human societies.

Accordingly, in addition to the cognitive mechanisms of the human mind and the natural social factors, the teachings of the prophets and the clergy, and the ontological role of supernatural agents in the world, it has also contributed to the acceptance and transmission of religious beliefs.

\section{Conclusion}

The ubiquitous presence of religious beliefs and their widespread and sustained transmission across cultures has prompted CSR scholars to organise a comprehensive effort to understand and explain this phenomenon.

Cognitive science of religion researchers examine how the structure of human minds influences the continued emergence and cultural success of religious beliefs, such as beliefs in supernatural agents, beliefs in spirits and beliefs in the afterlife that exist across cultures. They use content biases, largely based on our intuitive ontology, to understand the enduring and cross-cultural features of religious beliefs. These content biases reflect our cognitive tendencies to accept and transmit religious beliefs, although they cannot explain why individuals in a particular culture believe in special theological beliefs. In contrast, the context biases, which are mainly formed in the context of a particular culture, explain the acceptance and transmission of theological beliefs. This distinction shows why beliefs such as the belief in supernatural agents, spirits and afterlife are common amongst human beings and across human cultures, but theological beliefs remain confined to a particular culture. Of course, CSR scholars' attempt to naturally explain the acceptance and transmission of religious beliefs should not be construed as rejecting other explanations in this regard. These efforts ultimately show that all human beings in all cultures have a special tendency for accepting religious beliefs, a tendency that is not the product of a particular culture. This innate tendency then enters into a particular culture and is transformed into different theological beliefs that can be seen in different religious traditions.

\section{Acknowledgements Competing interests}

The author has declared that no competing interest exists.

\section{Authors' contributions}

I declare that I am the sole author of this research article.

\section{Ethical consideration}

This article followed all ethical standards for a research without direct contact with human or animal subjects.

\section{Funding information}

This research received no specific grant from any funding agency in the public, commercial, or not-for-profit sectors.

\section{Data availability statement}

Data sharing is not applicable to this article as no new data were created or analysed in this study.

\section{Disclaimer}

The views and opinions expressed in this article are those of the author and do not necessarily reflect the official policy or position of any affiliated agency of the author.

\section{References}

Barrett, H.C., Broesch, T., Scott, R.M., He, Z., Baillargeon, R., Wu, D. et al., 2013, 'Early false-belief understanding in traditional non-western societies', Proceedings Biological Sciences 280(1755), 1471-2954. https://doi.org/10.1098/rspb.2012.2654

Barrett, J., 2007, 'Cognitive science of religion: What is it and why is it?', Religion Compass 1(6), 768-786. https://doi.org/10.1111/j.1749-8171.2007.00042.x

Barrett, J., 2009, 'Cognitive science, religion, and theology', in J. Schloss \& M. Murray (eds.), Believing primate, pp. 76-99, Oxford University Press, New York.

Barrett, J., 2011, Cognitive science, religion and theology, Templeton Press, West Conshohocken, PA

Barrett, J. \& Nyhof, M, 2001, 'Spreading non-natural concepts: The role of intuitive conceptual structures in memory and transmission of cultural materials', Journal of Cognition \& Culture I(1), 69-100. https://doi.org/10.1163/156853701300063589

Bering, J.M., McLeod, K. \& Shackelford, T., 2005, 'Reasoning about dead agents reveals possible adaptive trends', Human Nature 16, 360-381.https://doi.org/ 10.1007/s12110-005-1015-2

Bloom, P., 2004, Descartes' baby: How the science of child development explains what makes us human, Arrow Books, London.

Boyer, P., 2000, 'Evolution of a modern mind and the origins of culture: Religious concepts as a limiting case', in P. Carruthers \& A. Chamberlain (eds.), Evolution and the human mind: Modularity, language and meta-cognition, pp. 93-112, Cambridge University Press, Cambridge. 
Boyer, P., 2002, Religion explained: The evolutionary origins of religious thought, Vintage, London.

Boyer, P., 2003, 'Religious thought and behavior as by-products of brain function' Trends in Cognitive Science 7(3), 119-124. https://doi.org/10.1016/S1364-6613 (03)00031-7

Boyer, P. \& Ramble, C., 2001, 'Cognitive templates for religious concepts: Crosscultural evidence for recall of counter-intuitive representation', Cognitive Science 25(4), 535-564. https://doi.org/10.1207/s15516709cog2504_2

Claidiere, N. \& Sperber, D., 2007, 'The role of attraction in cultural evolution', Journal of Cognitionand Culture 7(1-2),89-111. https://doi.org/10.1163/156853707X171829

De Cruz, H., 2014, 'Cognitive science of religion and the study of theological concepts', Topoi 33(2), 487-497. https:// doi.org/10.1007/s11245-013-9168-9

Edwards, M., 2009, Catholicity and heresy in the early church, Ashgate, Farnham.

Evans, E.M., 2000, 'The emergence of belief about the origins of species in schoolaged children', Merrill Palmer Quarterly 46(2), 221-254.

Gervais, W.M., Willard, A.K., Norenzayan, A. \& Henrich, J., 2011, 'The cultural transmission of faith: Why innate intuitions are necessary but insufficient to explain religious belief', Religion 41(3), 389-410. https:// doi.org/10.1080/0048721X.2011.604510

Henig, R.M., 2007, 'Darwin's God', New York Times, March 04.

Hodge, K.M., 2011, 'On imagining the afterlife', Journal of Cognition and Culture 11(3-4), 367-389. https://doi.org/10.1163/156853711X591305
Hume, D., 1956, Natural history of religion, in H.E. Root (ed.), Stanford University Press, Stanford, CA.

Kelemen, D., 2003, 'British and American children's preferences for teleo-functional explanations of the natural world', Cognition 88(2), 201-221. https://doi. org/10.1016/S0010-0277(03)00024-6

Kelemen, D., 2004, 'Are children "intuitive theists?" Reasoning about purpose and design in nature', Psychological Science 15(5), 295-301. https://doi.org/10.1111/ j.0956-7976.2004.00672.x

Lim, D., 2016, 'Cognitive science of religion and folk theistic belief', Zygon 51(4), 949-965. https://doi.org/10.1111/zygo.12304

Lisdorf, A., 2001, 'The spread of non-natural concepts', Journal of Cognition and Culture 4(1), 151-174. https://doi.org/10.1163/156853704323074796

Mercier, H. \& Sperber, D., 2011, 'Why do humans reason? Arguments for an argumentative theory', Behavioral and Brain Sciences 34(2), 57-74. https://doi. org $/ 10.1017 / \mathrm{S} 0140525 \times 10000968$

Powell, R. \& Steve, C., 2012, 'Religion as an evolutionary byproduct: A critique of the standard model', British Journal Philosophy of Science 63(3), 457-486. https://doi. org/ 10.2307/23253409

Sperber, D., 1997, 'Intuitive and reflective belief', Mind and Language 12(1), 67-83.

Thagard, P., 2018, 'Cognitive science', in E. Zalta (ed.), The Stanford encyclopedia of philosophy, viewed 24 September 2018, from https://plato.stanford.edu/entries/ cognitive-science. 